\title{
Downregulation of Microparticle Release and Pro-Inflammatory Properties of Activated Human Polymorphonuclear Neutrophils by LMW Fucoidan
}

\author{
João Alfredo Moraes ${ }^{\mathrm{a}, \mathrm{b}}$ Ana Clara Frony ${ }^{\mathrm{a}}$ Pedro Barcellos-de-Souza ${ }^{\mathrm{a}}$ \\ Marcel Menezes da Cunhac Thayanne Brasil Barbosa Calcia ${ }^{d}$ \\ Claudia Farias Benjamim $^{d}$ Catherine Boisson-Vidale Christina Barja-Fidalgo ${ }^{\text {a }}$ \\ a Laboratório de Farmacologia Celular e Molecular, Universidade do Estado do Rio de Janeiro, Rio de Janeiro, \\ Brazil; ' Laboratório de Biologia RedOx, Universidade Federal do Rio de Janeiro, Rio de Janeiro, Brazil; ' Núcleo \\ Multidisciplinar de Pesquisa em Biologia-NUMPEX-BIO, Universidade Federal do Rio de Janeiro, Xerém, Brazil; \\ 'Laboratório de Imunologia Molecular, Universidade Federal do Rio de Janeiro, Rio de Janeiro, Brazil; ${ }^{\text {eINSERM }}$ \\ U1140, Université Paris Descartes, Sorbonne Paris Cité, Paris, France
}

\section{Keywords}

LMW fucoidan · Microparticles · Inflammation ·

Polymorphonuclear neutrophils · Reactive oxygen species

\begin{abstract}
Exposition of neutrophils (polymorphonuclear neutrophils, PMNs) to bacterial products triggers exacerbated activation of these cells, increasing their harmful effects on host tissues. We evaluated the possibility of interfering with the classic immune innate responses of human PMNs exposed to bacterial endotoxin (lipopolysaccharide, LPS), and further stimulated with bacterial formyl peptide (N-formyl-methionineleucine-phenylalanine, fMLP). We showed that the lowmolecular-weight fucoidan (LMW-Fuc), a polysaccharide extracted from brown algae, attenuated the exacerbated activation induced by fMLP on LPS-primed PMNs, in vitro, impairing chemotaxis, NET formation, and the pro-survival and pro-oxidative effects. LMW-Fuc also inhibited the activation of canonical signaling pathways, AKT, bad, p47phox and
\end{abstract}

\section{KARGER}

E-Mail karger@karger.com www.karger.com/jin
(C) 2018 The Author(s) Published by S. Karger AG, Basel

Karger

Open access

This article is licensed under the Creative Commons AttributionNonCommercial-NoDerivatives 4.0 International License (CC BY NC-ND) (http://www.karger.com/Services/OpenAccessLicense). Usage and distribution for commercial purposes as well as any distribution of modified material requires written permission.
MLC, activated by the exposition of PMN to bacterial products. The activation of PMN by sequential exposure to LPS and $\mathrm{FMLP}$ induced the release of $\mathrm{L}$-selectin ${ }^{+}$microparticles, which were able to trigger extracellular reactive oxygen species production by fresh PMNs and macrophages. Furthermore, we observed that LMW-Fuc inhibited microparticle release from activated PMN. In vivo experiments showed that circulating PMN-derived microparticles could be detected in mice exposed to bacterial products (LPS/fMLP), being downregulated in animals treated with LMW-Fuc. The data highlight the autocrine and paracrine role of pro-inflammatory microparticles derived from activated PMN and demonstrate the anti-inflammatory effects of LMW-Fuc on these cells.

(C) 2018 The Author(s)

Published by S. Karger AG, Basel

João Alfredo Moraes and Ana Clara Frony contributed equally to this work.
Dr. Christina Barja-Fidalgo

Laboratório de Farmacologia Celular e Molecular

Department of Cell Biology, Universidade do Estado do Rio de Janeiro (UERJ)

Av. 28 de Setembro 87 fds. Vila Isabel, Rio de Janeiro, RJ 20551-030 (Brazil)

E-Mail barja-fidalgo@uerj.br 


\section{Introduction}

Polymorphonuclear neutrophils (PMNs) play a crucial role in the control of infectious processes. They are recruited and activated in response to pathogen-derived products, migrating to the injury site in order to clear microbes by phagocytosis, releasing cytotoxic agents, and further secreting chemokines and other inflammatory mediators which act in a positive loop to recruit more leukocytes [1].

Several families of adhesion proteins such as selectins and integrins are involved in PMN adhesion to endothelia. L-selectin molecules exposed on the surface of PMNs and other cell types interact with endothelial carbohydrate ligands, reducing the speed of leukocyte circulation in the bloodstream, and modulating the cell rolling on the inner vascular surface [2]. Interactions mediated by Lselectin prime neutrophils for the higher-affinity endothelial adhesion events mediated by integrins, which allow cell spreading and transendothelial migration [3].

PMNs can be activated by bacterial products like lipopolysaccharide (LPS) and N-formyl-methionine-leucinephenylalanine (fMLP), which are recognized by their specific receptors, TLR-4 and FPR-1, respectively [3, 4]. Cell activation triggers intracellular signaling pathways able to promote the production of reactive oxygen species (ROS) that represent one of the main tools for the killing of internalized pathogens by PMNs. Intracellular ROS can also act as signal transduction mediators in different physiological and pathological processes $[5,6]$. Nevertheless, exacerbated PMN stimulation may lead to ROS overflow to the extracellular milieu, resulting in tissue damage. Intracellular ROS production can also induce the release of neutrophil extracellular traps (NET) [7], a network of fibers containing DNA, histones, and elastase, and contribute to microbicidal activity of activated PMNs [8]. A number of reports have described that LPS and fMLP can induce NET generation $[9,10]$.

Once activated, PMNs trigger intracellular pro-survival pathways that halt their constitutive apoptosis program, expanding cell lifespan. During an inflammatory response, an excessively long PMN apoptosis delay may result in further tissue injury, hindering the resolution of inflammation and establishing a scenario that ranges from acute to chronic inflammation [3]. Thus, pro-inflammatory stimuli must be counteracted later during tissue injury, with the mobilization of proteins that initiate PMN apoptosis, preventing tissue injury caused by the excess of products released by activated PMNs.

LMW Fucoidan Downregulates Activated Neutrophils
Similar to other eukaryotic cells, activated PMNs release microparticles from the cellular membrane surface through a process known as "ectocytosis" [11]. PMN-derived microparticles can express markers from their parental cells and may harbor bioactive membrane or cytoplasmic molecules that could potentially modulate several responses in other cells [12]. Mesri and Altieri [11] showed that fMLP induced PMNs to release enriched Lselectin and phosphatidylserine microparticles. However, the contents and function of the microparticles released by fMLP-treated PMNs have not been fully elucidated.

Fucoidans are a group of natural fucose-enriched sulphated polysaccharides that were shown to bind to L-selectin on neutrophils, preventing leukocyte migration to inflammatory foci [13]. A low-molecular-weight fucoidan (LMW-Fuc) extracted from the brown algae Ascophyllum nodosum was described to present negligible anticoagulant activity, but potent antithrombotic and pro-angiogenic effects, being suggested as potential neovascularization agent $[14,15]$. Nevertheless, no studies have addressed the specific effects of LMW-Fuc on the inflammatory response.

The present study aimed to evaluate the modulatory effects of LMW-Fuc on activated PMNs. To mimic the pro-inflammatory environment encountered by PMNs during bacterial-triggered inflammatory responses [16], cells were primed with endotoxin (LPS) and subsequently stimulated with a bacterial peptide (fMLP). Additionally, we examined the functions of microparticle release by activated PMNs, and the effects of LMW-Fuc on this process. Thus, we expected to contribute to a better understanding of the role of the microvesicles released by PMN under a sequential activation with bacterial products, and also to highlight the effects of LMW-Fuc on these cells.

\section{Material and Methods}

\section{Material}

Benzamidine, bovine serum albumin, EDTA, fMLP, HEPES, leupeptin, LPS, PMSF, and soybean trypsin inhibitor were purchased from Sigma-Aldrich (St. Louis, MO, USA). APF, luminol, lucigenin, $\mathrm{CM}-\mathrm{H}_{2} \mathrm{DCFDA}$, and JC1 were obtained from Molecular Probes (Carlsbad, CA, USA). Dulbecco's modified Eagle's medium and fetal calf serum were from GIBCO-BRL (Carlsbad, CA, USA). The enhanced chemiluminescence system was from Pierce Biotechnology (Rockford, IL, USA). Dr. Boisson-Vidal (INSERM U1140) obtained LMW-Fuc that had been extracted from the brown algae Ascophyllum nodosum, as described previously [14].

Innate Immun 2019;11:330-346

DOI: $10.1159 / 000494220$ 
Data Analysis and Statistical Procedures

Experimental in vitro Model of Neutrophil Treatment

All incubations were performed at $37^{\circ} \mathrm{C}$, in a $5 \% \mathrm{CO}_{2}$ atmosphere.

Experimental groups were as follows. Untreated: RPMI medium alone; LMW-Fuc: LMW-Fuc $(10 \mu \mathrm{g} / \mathrm{mL})$; LPS/fMLP: LPS $(1 \mu \mathrm{g} / \mathrm{mL})$ for $5 \mathrm{~min}$ and then fMLP $(100 \mathrm{nM})$ stimulation; LPS/ LMW-Fuc/fMLP: LPS $(1 \mu \mathrm{g} / \mathrm{mL})$ for $5 \mathrm{~min}$, LMW-Fuc $(10 \mu \mathrm{g} / \mathrm{mL})$ for another $5 \mathrm{~min}$ and then fMLP $(100 \mathrm{nM})$ stimulation.

Experimental in vivo model in BALB/c Mice

Sham: Intraperitoneal injection (IP) of saline $0.9 \%$. After 15 min, intravenous injection (IV) of saline $0.9 \%$. After 15 min (30 min after time 0 ), IV of saline $0.9 \%$.

LMW-Fuc: IP of saline $0.9 \%$. After 15 min, IV of LMW-Fuc 25 $\mu \mathrm{g} / \mathrm{g}$. After $15 \mathrm{~min}$ (30 min after time 0 ), IV of saline $0.9 \%$.

LPS/fMLP: IP of LPS $0.2 \mu \mathrm{g} / \mathrm{g}$. After $15 \mathrm{~min}$, IV of saline $0.9 \%$. After $15 \mathrm{~min}$ (30 min after time 0 ), IV of fMLP $0.0032 \mu \mathrm{g} / \mathrm{g}$.

LPS/LMW-Fuc/fMLP: IP of LPS $0.2 \mu \mathrm{g} / \mathrm{g}$. After $15 \mathrm{~min}$, IV of LMW-Fuc $25 \mu \mathrm{g} / \mathrm{g}$. After $15 \mathrm{~min}$ (30 min after time 0 ), IV of fMLP $0.0032 \mu \mathrm{g} / \mathrm{g}$.

After $30 \mathrm{~min}$ (60 min considering time 0 ), the mice were euthanized, and the plasma was collected. All IP injections were performed in a final volume of $0.4 \mathrm{~mL}$, and IV injections were performed in a final volume of $0.2 \mathrm{~mL}$.

Purification of Human Macrophages and PMNs

Monocytes and PMNs were isolated using a Percoll gradient, as previously described [17]. Monocytes were plated and incubated at $37^{\circ} \mathrm{C}$ in a $5 \% \mathrm{CO}_{2}$ atmosphere for 7 days, to differentiate to macrophages.

\section{Cell Migration Assay}

Neutrophil chemotaxis was evaluated as described [18]. Briefly, chemoattractants $(28 \mu \mathrm{L})$ were placed in the bottom of a 48 well modified Boyden chamber (Neuroprobe Inc., Gaithersburg, $\mathrm{MD}, \mathrm{USA}$ ) with $5 \mu \mathrm{m}$ pore-sized polyvinylpyrrolidone-free polycarbonate membranes and $50 \mu \mathrm{L}$ of the neutrophil suspension ( 5 $\times 10^{4}$ cells $/ \mathrm{mL}$ ) was added to the top chamber. In some groups, PMNs were primed with LPS. The chambers were then incubated for $1 \mathrm{~h}$ at $37^{\circ} \mathrm{C}$ with $5 \% \mathrm{CO}_{2}$, after which membranes were removed, fixed, and stained with Diff-Quick staining kit (Laborclin, Pinhais, Parana, Brazil). The number of neutrophils that migrated to the chemoattractant (LPS or fMLP) in the lower side of the filter was counted in at least five random fields $(\times 1,000$ magnification). The results are representative of at least three independent experiments performed in triplicate for each sample and are expressed as mean \pm SD of the number of neutrophils per field. Migration to medium alone (random migration) was used as negative control.

\section{NET Assay}

To evaluate NET formation, PMNs $\left(10^{6} \mathrm{cell} / \mathrm{mL}\right)$ were incubated for $1 \mathrm{~h}$ as shown in the section Experimental in vitro Model of Neutrophil Treatment. NET formation was assessed by DNA quantification and elastase activity analyses. The amount of DNA released in the supernatant was quantified using a NanoVue (GE Healthcare, Little Chalfont, UK). Elastase activity was monitored by fluorescence analysis using an EnVision ${ }^{\mathrm{TM}}$ multilabel plate reader (Perkin-Elmer, Waltham, MA, USA) by incubating PMNs with the fluorogenic elastase substrate V (Calbiochem; final concentration, $50 \mu \mathrm{M})$.

\section{Apoptosis Assays}

PMNs $\left(10^{6}\right.$ cells $\left./ \mathrm{mL}\right)$ were incubated as described in the section Experimental in vitro Model of Neutrophil Treatment for $20 \mathrm{~h}$ at $37^{\circ} \mathrm{C}$. Then, PMN apoptosis was evaluated through: (a) visual identification and counting by light microscopy (using an Olympus BX41 microscope; Tokyo, Japan) of cells with pyknotic nuclei and decreased cell volume; (b) annexin V-FITC labeling of exposed phosphatidylserine residues (Abcam, Cambridge, UK), followed by flow cytometry analysis; (c) mitochondrial transmembrane potential assessment by flow cytometry using the JC1 probe (10 $\mu \mathrm{g} / \mathrm{mL}$, Molecular Probes), according to the manufacturer's instructions.

\section{Fluorescence Microscopy}

PMNs $\left(10^{6}\right.$ cells $\left./ \mathrm{mL}\right)$ seeded in 24 -well plates $\left(2.5 \times 10^{5}\right.$ cells/ well) were stimulated as described in the section Experimental in vitro Model of Neutrophil Treatment and incubated for $30 \mathrm{~min}$. Then, cells were fixed for $20 \mathrm{~min}$ in $4 \%$ paraformaldehyde/4\% sucrose, and then incubated for $2 \mathrm{~h}$ with phalloidin-rhodamine in PBS $(1: 1,000)$. Coverslips were mounted on slides using a solution of $20 \mathrm{mM}$ N-propyl gallate in $80 \%$ glycerol in PBS before examination under an Olympus IX71 fluorescence microscope (Olympus). Densitometry analysis was performed (approximately 5 cells/field) using the Image Pro Plus ${ }^{\mathrm{TM}}$ software (Rockville, MD, USA).

Western Blotting Analysis

Cell extracts, obtained from neutrophils $\left(10^{6}\right.$ cells $)$ stimulated as explained in the section Experimental in vitro Model of Neutrophil Treatment, were submitted to immunoblotting to assess PMN protein expression, as described previously [17].

\section{ROS Production}

PMNs $\left(10^{5}\right.$ cells/well) were seeded in 96-well plates and were stimulated as described in the section Experimental in vitro Model of Neutrophil Treatment. For fluorescence assay, cells were loaded with $10 \mu \mathrm{M}$ CM- $\mathrm{H}_{2}$ DCFDA or $10 \mu \mathrm{M}$ APF for $1 \mathrm{~h}$ and then washed to remove free probe. For luminescence assays, $5 \mu \mathrm{M}$ lucigenin or $50 \mu \mathrm{M}$ luminol probes were added to PMNs. CM- $\mathrm{H}_{2} \mathrm{DCF}-$ DA fluorescence was monitored at excitation and emission wavelengths of 495 and $530 \mathrm{~nm}$, respectively. APF fluorescence was monitored at excitation and emission wavelengths of 490 and 515 $\mathrm{nm}$, respectively. Lucigenin- or luminol-emitted luminescence was measured at intervals of $5 \mathrm{~s}$ throughout a period of $1 \mathrm{~h}$. Both fluorescence and chemiluminescence were quantified using an EnVision ${ }^{\circledR}$ multilabel plate reader (Perkin-Elmer, Waltham, MA, USA).

\section{Microparticle Isolation}

Microparticles were isolated from plasma obtained from mice (section Experimental in vivo Model in BALB/c Mice) or from human PMNs $\left(10^{6}\right.$ cells $\left./ \mathrm{mL}\right)$ incubated with different stimuli, as described in the section Experimental in vitro Model of Neutrophil Treatment. For that, plasma or cell suspensions were subjected to 2 consecutive rounds of centrifugation at $400 \mathrm{~g}$, to remove any cell contamination. Then, supernatants were subjected to ultracentrifugation at 100,000 $\mathrm{g}$ for $4 \mathrm{~h}$. Microparticle-containing pellets were resuspended in annexin $\mathrm{V}$ binding buffer, and microparticles were 
labeled with annexin $\mathrm{V}$ for quantification by flow cytometry. A control sample containing 1- $\mu \mathrm{m}$ microbeads (Life Technologies, Carlsbad, CA, USA) was used to define with appropriate precision the gate in the FSC/SSC profile that contained microparticles $(<1-\mu \mathrm{m}$ events), and $10-\mu \mathrm{m}$ microbeads (different from microparticles size) were used to estimate the number of microparticles $/ \mu \mathrm{L}$.

Scanning Electron Microscopy Analysis

PMNs $\left(10^{6} \mathrm{cell} / \mathrm{mL}\right)$ were stimulated for $30 \mathrm{~min}$ as described in the section Experimental in vitro Model of Neutrophil Treatment, washed three times with PBS, and fixed for $1 \mathrm{~h}$ and post-fixed in $1 \%$ tannic acid followed by $2 \%$ osmium tetroxide for $30 \mathrm{~min}$, at $4{ }^{\circ} \mathrm{C}$. Samples were washed in water, dehydrated in a graded ethanol series, critical-point dried in $\mathrm{CO}_{2}$, and sputter-coated with gold ( 5-nm layer). Samples were analyzed in a JEOL JSM $6510 \mathrm{LV}$ scanning electron microscope (JEOL, Japan).

Statistical Analysis

Statistical significance was assessed by ANOVA, followed by Bonferroni's $t$ test, and $p<0.05$ was considered statistically significant.

\section{Results}

\section{LMW-Fuc Inhibits PMN Migration and NET}

\section{Formation Triggered by Bacterial Products}

As an initial step, we investigated whether LMW-Fuc would have effects on PMN functions. At concentrations between 1 and $100 \mu \mathrm{g} / \mathrm{mL}$, LMW-Fuc per se did not induce chemotaxis (see online suppl. Fig. S1A; for all online suppl. material, see www.karger.com/doi/10.1159/000494220) or directly affect any other function in nonstimulated PMNs.

Then, we investigated the possible effects of LMW-Fuc on PMN chemotaxis toward classical pro-inflammatory chemoattractants, LPS and fMLP. We observed that LMW-Fuc inhibited PMN migration induced by LPS or fMLP and negatively modulated the strong chemotactic effect of fMLP on PMNs previously activated with LPS

Fig. 1. Low-molecular-weight fucoidan (LMW-Fuc) inhibits the pro-inflammatory effects of activated polymorphonuclear neutrophils (PMNs). Human PMNs were left untreated or were incubated with $10 \mu \mathrm{g} / \mathrm{mL} \mathrm{LMW}$-Fuc for $5 \mathrm{~min}$. To evaluate the effect of PMN activation on different assays, some samples were primed with $1 \mu \mathrm{g} / \mathrm{mL}$ lipopolysaccharide (LPS) for $5 \mathrm{~min}$ prior to LMWFuc treatment. All treatments were performed at $37^{\circ} \mathrm{C}$ (in a $5 \%$ $\mathrm{CO}_{2}$ atmosphere). a For chemotaxis analysis, cells were placed in modified Boyden chambers after LMW-Fuc treatment, and PMN chemotaxis towards $\mathrm{N}$-formyl-methionine-leucine-phenylalanine (fMLP; $100 \mathrm{nM})$ or LPS $(1 \mu \mathrm{g} / \mathrm{mL})$ was assessed for $1 \mathrm{~h}$ at $37^{\circ} \mathrm{C}$. Membranes were stained, and migrating cells were counted by light microscopy examination. Results are representative of at least five different experiments. $\mathbf{b}$ To analyze the dynamics of the actin

LMW Fucoidan Downregulates Activated Neutrophils
(Fig. 1a). PMN migration is well known to be associated with actin cytoskeleton rearrangement [19]. The treatment with LMW-Fuc partially inhibited actin polymerization triggered by fMLP on LPS-stimulated PMNs, interfering with cytoskeleton dynamics (Fig. 1b).

During an exacerbated inflammatory response as occurs in sepsis, bacterial products induce PMNs to release large amounts of NETs. Although it is well established that LPS and fMLP can induce NET $[9,10]$, there are no studies that had investigated both stimuli. To evaluate whether LMW-Fuc could interfere with NET formation induced by fMLP in LPS-activated human PMNs, we analyzed the amount of extracellular DNA released and the elastase activity in cultures of these cells. We detected potent induction of NET formation by LPS-primed PMNs treated with fMLP (Fig. 1c, d). Corroborating the data, we confirmed by immunofluorescence microscopy the presence of histones and elastase in the extracellular medium surrounding the stimulated PMNs (Figure S2). NET formation induced by LPS and FMLP was inhibited by treatment with LMW-Fuc (Fig. 1c, d, and see online suppl. Fig. S2).

\section{LMW-Fuc Inhibits Apoptosis Protection in Activated $P M N s$}

PMNs are committed to a spontaneous apoptosis program which is inhibited upon PMN activation. Thus, apoptosis delay is considered an indicator of PMN activation. We evaluated PMN apoptosis after $20 \mathrm{~h}$ of treatment with LPS/fMLP using three different methodologies: (a) morphological alterations; (b) quantification of annexin $\mathrm{V}^{+}$cells; and (c) quantification of the loss of mitochondrial transmembrane potential. We observed that LMWFuc, at concentrations between 1 and $100 \mu \mathrm{g} / \mathrm{mL}$ did not affect PMN spontaneous apoptosis (see online suppl. Fig. $\mathrm{S} 1 \mathrm{~B})$. On the other hand, LMW-Fuc impaired the pro-

cytoskeleton during PMN activation, LMW-Fuc-treated PMNs primed with LPS were treated with $100 \mathrm{nM}$ fMLP. After $30 \mathrm{~min}$ at $37^{\circ} \mathrm{C}$, PMNs were cytocentrifuged in coverslips and were labeled for $2 \mathrm{~h}$ with phalloidin-rhodamine. Then, coverslips were washed and mounted onto slides, and F-actin fluorescence was analyzed by densitometry of light microscopy images. Scale bar: $10 \mu \mathrm{m}$. c, d To evaluate the formation of neutrophil extracellular traps (NETs) by PMNs, LMW-Fuc-treated PMNs primed with LPS were treated with $100 \mathrm{nM}$ fMLP. NET formation was estimated by "free" DNA quantification using $\mathrm{NanoVue}^{\mathrm{TM}}$ (c) and by elastase activity analysis (d). Results are representative of three independent experiments. All data are expressed as means \pm SDM. ${ }^{*} p<0.05$ vs. untreated; ${ }^{\#} p<0.05$ vs. the corresponding group (treated or migrating towards LPS and/or fMLP) not treated with LMW-Fuc.

(For figure see next page.)

J Innate Immun 2019;11:330-346 333 


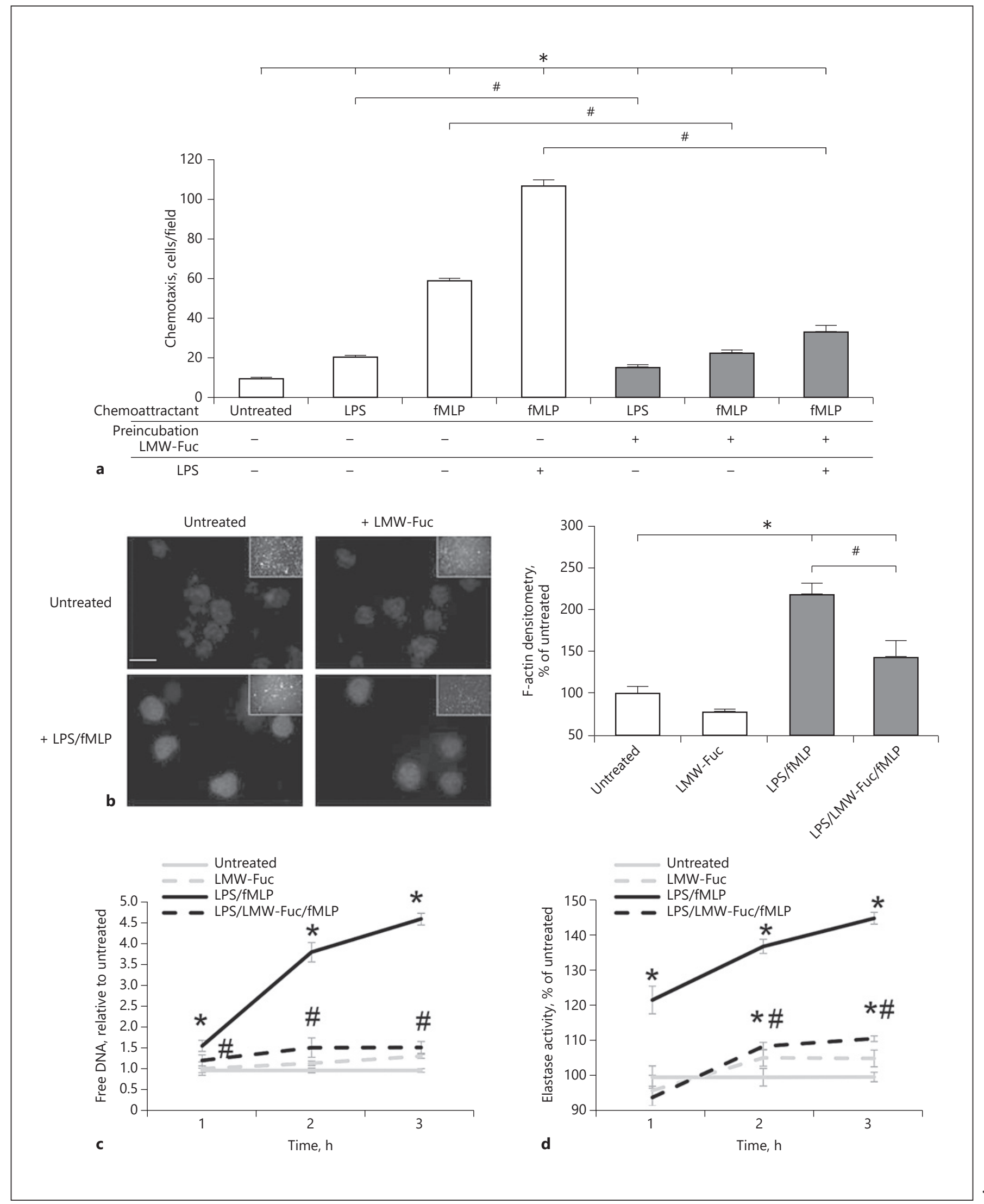




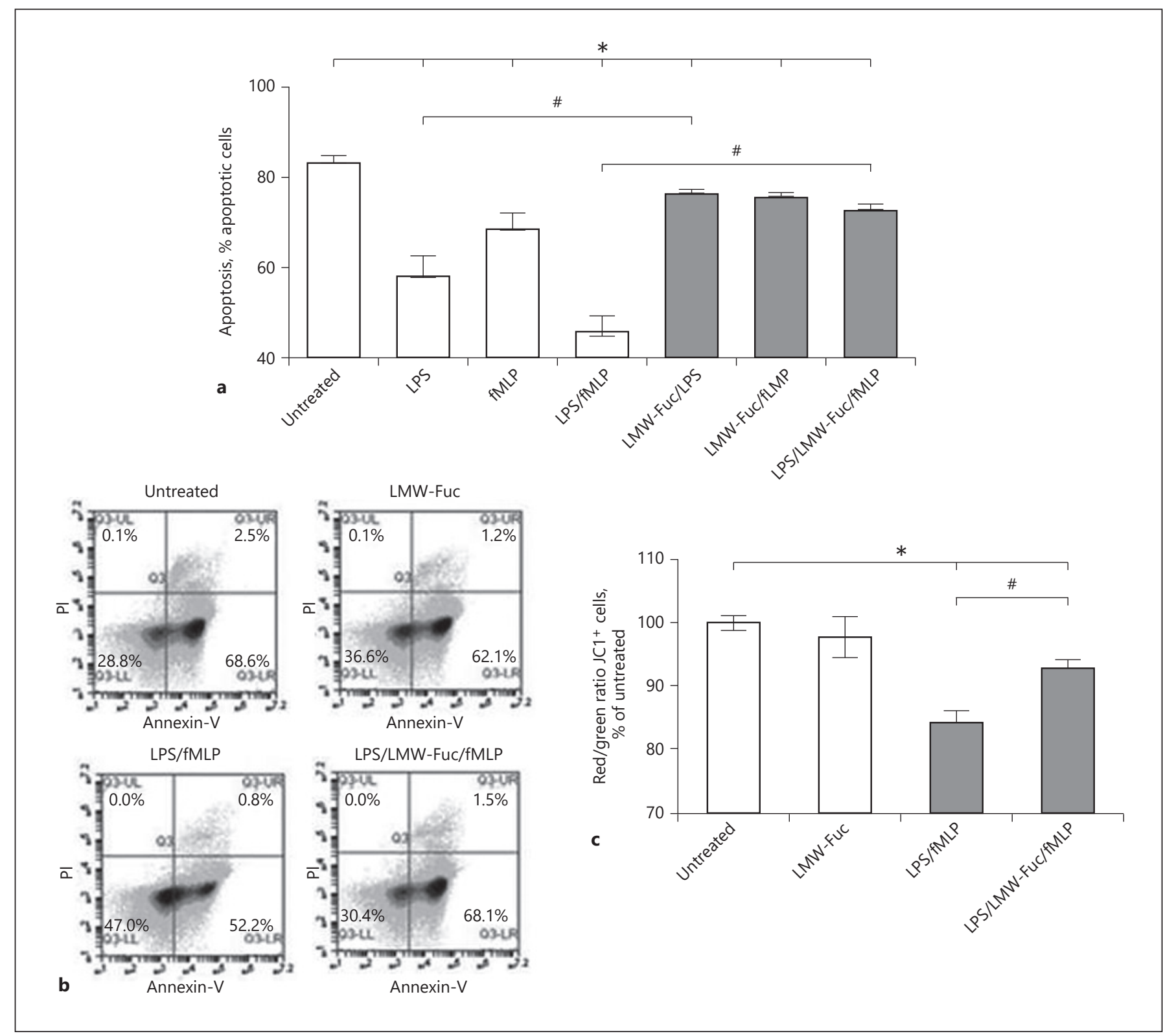

Fig. 2. Low-molecular-weight fucoidan (LMW-Fuc) inhibits protection from apoptosis in activated polymorphonuclear neutrophils (PMNs). PMNs were left untreated or were incubated with $10 \mu \mathrm{g} / \mathrm{mL} \mathrm{LMW}$-Fuc for $5 \mathrm{~min}$ before one of the following treatments: $1 \mu \mathrm{g} / \mathrm{mL}$ lipopolysaccharide (LPS) for $20 \mathrm{~h} ; 100 \mathrm{nM} \mathrm{N}$-formyl-methionine-leucine-phenylalanine (fMLP) for $20 \mathrm{~h}$; or LPS priming for 5 min followed by stimulation with fMLP for $20 \mathrm{~h}$ (LPS/fMLP). Furthermore, PMNs were primed with LPS for 5 min before treatment with LMW-Fuc for $5 \mathrm{~min}$, and then stimulated with fMLP for $20 \mathrm{~h}$ (LPS/LMW-Fuc/fMLP group). All treatments were performed at $37^{\circ} \mathrm{C}$ (in a $5 \% \mathrm{CO}_{2}$ atmosphere). a PMNs were stained with Diff-Quik ${ }^{\mathrm{TM}}$ (Dade Behring, Dudingen, Switzerland), and apoptotic cells (i.e., those with piknotic nuclei and decreased volume) were counted by direct light microscopy observation. The results are representative of three to five different experiments. $\mathbf{b}$ PMNs were fixed and labeled with annexin $\mathrm{V}$ and propidium iodide (PI) and then analyzed by flow cytometry, to identify apoptotic cells (annexin $\mathrm{V}^{+} / \mathrm{PI}^{-}$and annexin $\mathrm{V}^{+} / \mathrm{PI}^{+}$). c PMNs were fixed and marked with the JC1 probe to detect apoptosis-related loss of mitochondrial membrane potential (i.e., decrease in the ratio of red/green $\mathrm{JC1}^{+}$cells) by flow cytometry. Results are representative of three independent experiments. Data are displayed as means \pm SDM. ${ }^{*} p<0.05$ vs. untreated; ${ }^{*} p<0.05$ vs. the corresponding group (treated with LPS and/or fMLP) not treated with LMW-Fuc. 


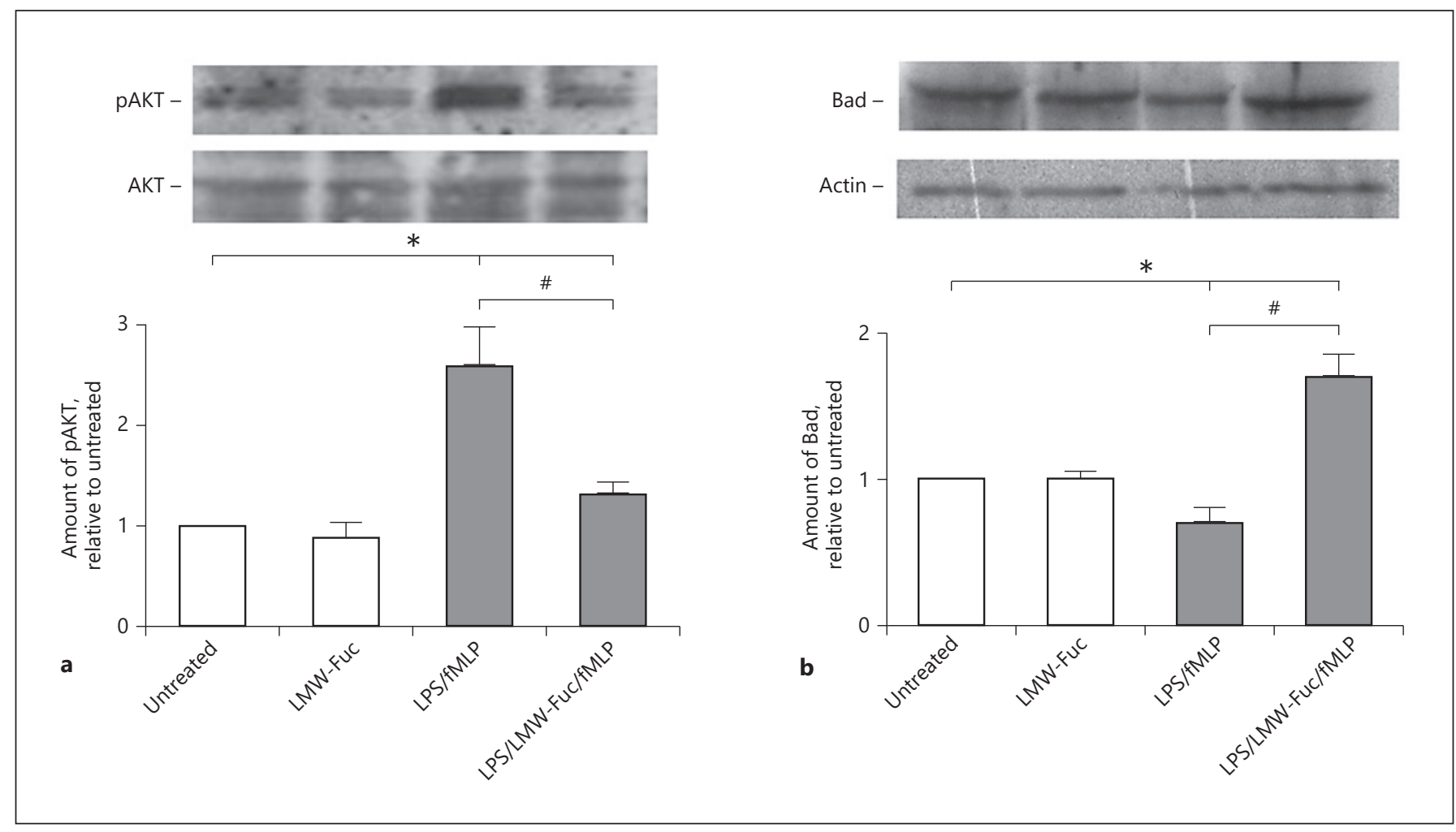

Fig. 3. Low-molecular-weight fucoidan (LMW-Fuc) inhibits protection from apoptosis in activated polymorphonuclear neutrophils (PMNs). PMNs were left untreated or were primed with $1 \mu \mathrm{g} /$ $\mathrm{mL}$ lipopolysaccharide (LPS) for $5 \mathrm{~min}$ followed by stimulation with $100 \mathrm{nMN}$-formyl-methionine-leucine-phenylalanine (fMLP) for $15 \mathrm{~min}$ (a) or for $20 \mathrm{~h}$ (b) (LPS/fMLP). Furthermore, PMNs were primed with LPS for 5 min before treatment with $10 \mu \mathrm{g} / \mathrm{mL}$ LMW-Fuc for $5 \mathrm{~min}$, and then stimulated with fMLP for $15 \mathrm{~min}$ (a) or for $20 \mathrm{~h}$ (b) (LPS/LMW-Fuc/fMLP group). All treatments were performed at $37^{\circ} \mathrm{C}$ (in a $5 \% \mathrm{CO}_{2}$ atmosphere). PMN whole cell extracts were prepared and subjected to SDS-PAGE and immunoblotting for the detection of AKT and phospho-AKT (pAKT; a) and Bad and actin (b). Western blotting results were quantified by densitometry using ImageJ, after normalization of pAKT and Bad levels relative to the loading controls (AKT and actin, respectively). Results are representative of three independent experiments. Data are displayed as means \pm SDM. ${ }^{*} p<0.05$ vs. untreated; ${ }^{*} p<0.05$ vs. the corresponding group treated with LPS/fMLP not treated with LMW-Fuc. survival effects of LPS, fMLP, or LPS/fMLP treatments, increasing PMN apoptosis rates to levels similar to those observed in control populations (Fig. 2a-c).

Apoptotic PMNs are characterized by high expression levels of $\mathrm{Bad}$, a proapoptotic member of $\mathrm{Bcl}-2$ protein family $[17,20]$. In activated PMNs, the delay in the initiation of the apoptotic program is partly due to the activation of the PI3K-AKT pathway, which promotes Bad phosphorylation and degradation, contributing to prolong cell survival [17], and modulates cell migration [21]. LPS/fMLP treatment induced an increase in AKT phosphorylation that was inhibited by LMW-Fuc treatment (Fig. 3a). In agreement, we observed that LMW-Fuc treatment not only impaired the degradation of Bad induced by the bacterial challenges, but also increased Bad protein levels in cells stimulated with LPS/fMLP, after $20 \mathrm{~h}$ of treatment (Fig. 3b).

\section{LMW-Fuc Inhibits the Extracellular ROS Production Induced by LPS/FMLP}

Initially, we observed elevated levels of ROS when LPS-primed PMNs were treated with fMLP (Fig. 4a-d). Treatment with LMW-Fuc partially inhibited the total ROS production (detected by luminol) induced by LPS/ fMLP treatment until 90 min (5,400 s; Fig. 4a). However, using more specific molecular tools to distinguish between intra- and extracellular ROS generation (CM$\mathrm{H}_{2}$ DCFDA and lucigenin, respectively), we found that treatment with LMW-Fuc did not interfere with the increase in intracellular ROS production (Fig. 4b), but com- 

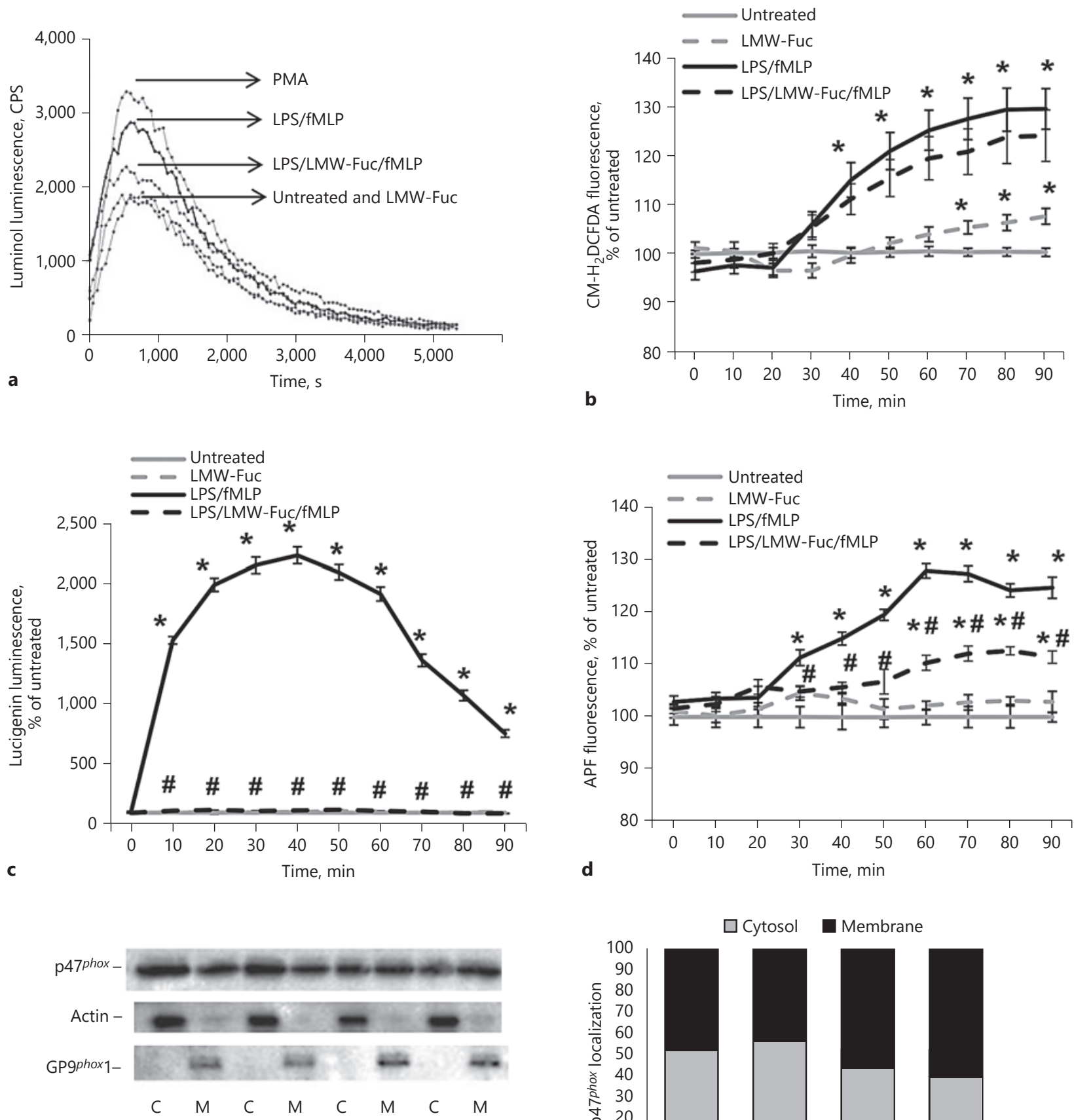

e

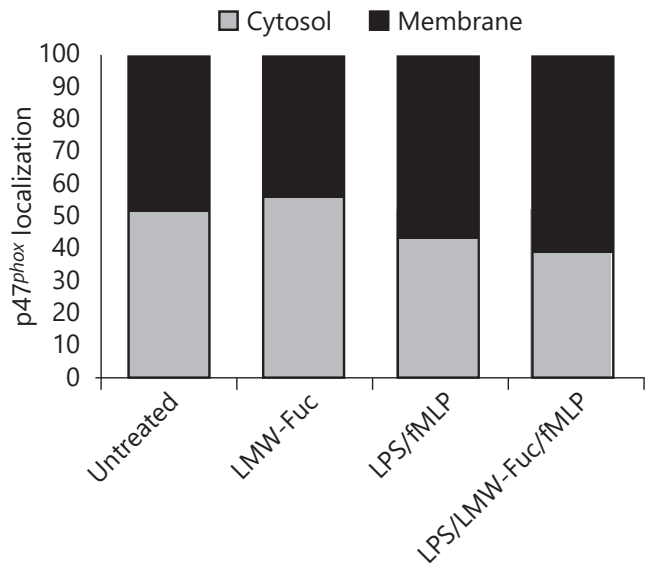

(For legend see next page.) 
pletely inhibited the extracellular ROS production induced by LPS/fMLP (Fig. 4c). When we investigated hypochlorous acid production (a MPO derived ROS), through APF probe, we observed that LMW-Fuc was able to inhibit the LPS/fMLP effect until $60 \mathrm{~min}$, and it caused a partial inhibition after this period (Fig. $4 \mathrm{~d}$ ).

In activated $\mathrm{PMN}$, ROS production by NOX 2 relies on $\mathrm{p} 47^{\text {phox }}$ activation by phosphorylation, and only the phosphorylated $\mathrm{p}^{\text {phox }}$ is able to translocate to the cell membrane for assembly into NOX2 subunits [22]. LPS/fMLP treatment induced $\mathrm{p} 47^{\text {phox }}$ translocation to the cell membrane, and this phenomenon was not inhibited by LMWFuc treatment (Fig. 4e).

\section{LMW-Fuc Inhibits PMN Microparticle Generation Induced by LPS/fMLP}

We observed that LPS/fMLP stimulation rapidly reduces the expression of L-selectin on PMNs, as detected by flow cytometry (see online suppl. Fig. S3). Although fucoidans in general are capable of binding to L-selectin [23], treatment with LMW-Fuc did not inhibit L-selectin shedding from PMNs activated by LPS/fMLP. However, we observed that treatment with LMW-Fuc caused a delay in the L-selectin shedding induced by LPS/fMLP (see online suppl. Fig. S3).

To investigate whether LMW-Fuc could interfere with the production of microparticles by activated PMNs, cell membrane alterations were analyzed by scanning electron microscopy after the treatments with LPS, fMLP, and LMW-Fuc. Untreated cells (Fig. 5a) displayed cell membrane "blebs" suggestive of constitutive microparticle budding. After $30 \mathrm{~min}$ of LPS/fMLP challenge, cells displayed membrane ruffles, which are indicative of intense cytoskeletal activity, and a flatter cell surface, suggesting that the stimuli accelerated the release of microparticles by activated PMNs (Fig. 5a). Treatment with

Fig. 4. Low-molecular-weight fucoidan (LMW-Fuc) inhibits extracellular (but not intracellular) reactive oxygen species (ROS) production by activated polymorphonuclear neutrophils (PMNs). Human PMNs remained untreated or were treated with $10 \mu \mathrm{g} / \mathrm{mL}$ LMW-Fuc (LMW-Fuc group), $1 \mu \mathrm{g} / \mathrm{mL}$ lipopolysaccharide (LPS) for $5 \mathrm{~min}$ (priming) followed by stimulation with $100 \mathrm{nM} \mathrm{N}$-formyl-methionine-leucine-phenylalanine (fMLP) for $90 \mathrm{~min}$ (LPS/ fMLP group); or LPS primed, treated with LMW-Fuc, and then fMLP-stimulated (LPS/LMW-Fuc/fMLP group). In a, treatment with $100 \mathrm{nM}$ phorbol myristate acetate (PMA) was also used as a positive control for ROS production. All treatments were performed at $37^{\circ} \mathrm{C}$ (in a $5 \% \mathrm{CO}_{2}$ atmosphere). ROS production was assessed using three different probes: luminol was used to assess
LMW-Fuc inhibited LPS/fMLP-induced shape changes on PMNs, and maintained the cells displaying surface blebs but not membrane ruffles (Fig. 5a).

Activation of the ROCK (Rho-Kinase)/MLC (Myosin Light Chain) pathway has been associated with cytoskeleton rupture, vesiculation, and microparticle formation [24]. Indeed, stimulation of PMNs with LPS/fMLP increased MLC phosphorylation, and this effect was reversed by treatment of LPS/fMLP-stimulated cells with LMW-Fuc (Fig. 5b).

Nolan et al. [25] showed that PMN microparticle production occurs from spots in the plasma membrane rich in L-selectin. Treatment of PMNs with LPS/fMLP rapidly induced L-selectin shedding and also the release of annexin $\mathrm{V}^{+}$microparticles after $30 \mathrm{~min}$ of stimulation (Fig. 5c). The gating strategy and the scatter plots can be observed in online supplementary Figure S4. These microparticles were also L-selectin ${ }^{+}$, and positive for the PMN marker CD66b (see online suppl. Fig. S5A, B). LMW-Fuc treatment significantly inhibited the release of microparticles from activated PMNs (Fig. 5c), although it did not block L-selectin shedding from these cells at this time point (30 min; Fig. S3). Furthermore, the ROCK inhibitor Y-27632 also inhibited microparticle production from activated PMNs (Fig. 5c), which evidences a role for ROCK in the vesiculation process.

To gain insight into the composition of the microparticles released by PMNs, the contents of actin, GAPDH, tubulin, NOX2 (GP91 ${ }^{\text {phox }}$ ), p47 ${ }^{\text {phox }}, \mathrm{p} 22$, and p67 were analyzed by immunoblotting. Among the proteins whose presence in microparticles was investigated, only actin (present in equal levels in all groups) and $\mathrm{p} 47^{\text {phox }}$, a NOX2 cytosolic subunit, were readily detected in microparticles generated by LPS/fMLP-treated cells, but not in untreated cells (Fig. 5d). Apart from reducing microparticle release, treatment with LMW-Fuc was also able to decrease

total ROS production (a), CM- $\mathrm{H}_{2}$ DCFDA (b), lucigenin (c), and APF (d). The results are representative of three independent experiments. Data are displayed as means \pm SDM. ${ }^{*} p<0.05$ vs. untreated; ${ }^{\#} p<0.05$ vs. the corresponding group treated with LPS/ fMLP, but not treated with LMW-Fuc. CPS, luminescence counts/s. e After $1 \mathrm{~h}$ of treatment, PMNs were lysed and subjected to ultracentrifugation at 40,000 $g$ for $1 \mathrm{~h}$. Cytosolic (C; the supernatant) and membrane $(\mathrm{M}$; the pellet $)$ fractions $(10 \mu \mathrm{g} / \mathrm{lane})$ were subjected to SDS-PAGE and Western blotting for the expression of p47 ${ }^{\text {phox }}$, actin (cytosolic load control), and gp91 phox (membrane load control) proteins. The results are representative of three independent experiments. 


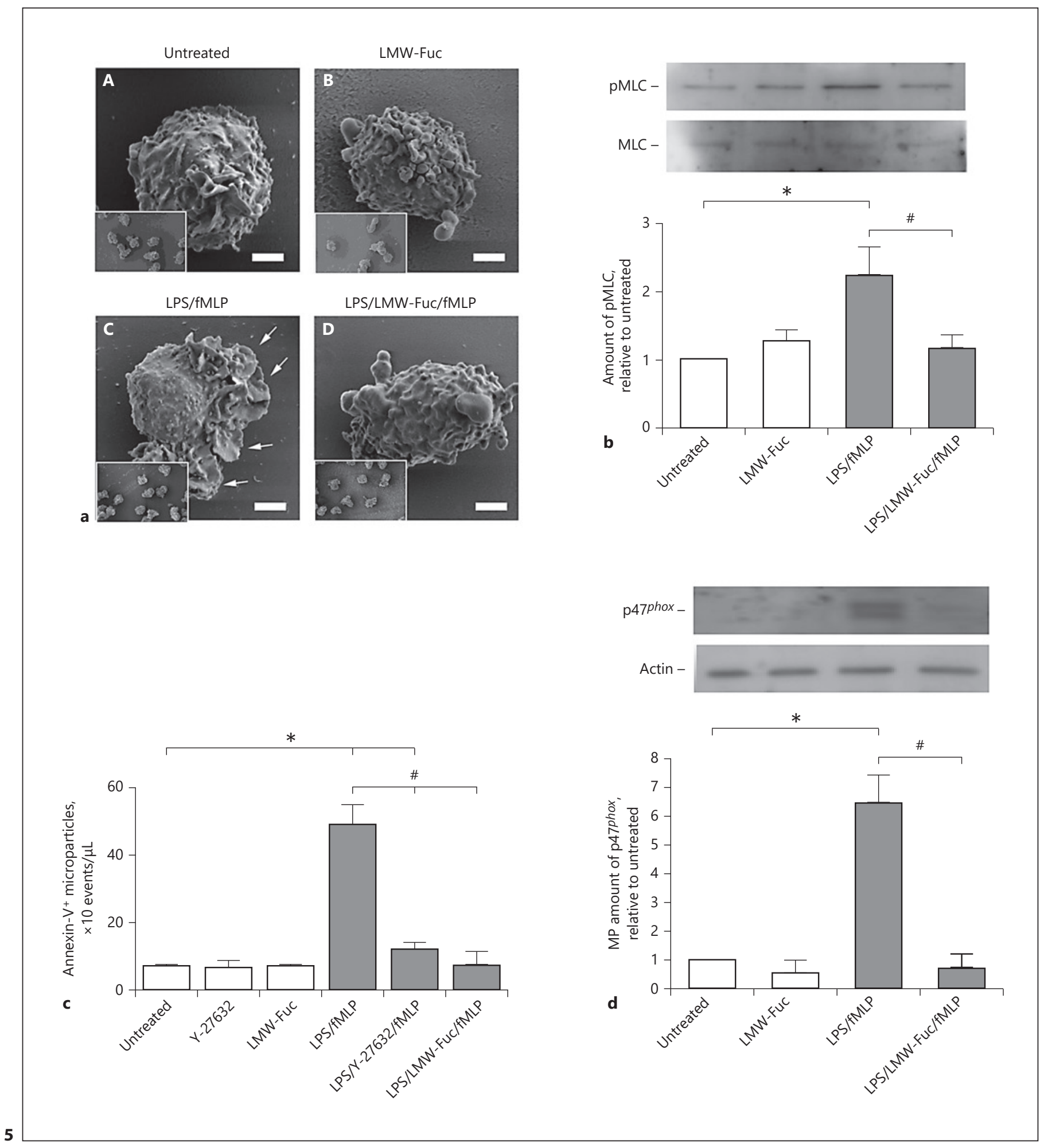


the levels of $\mathrm{p} 47^{\text {phox }}$ in the microparticles released from activated PMNs (Fig. 5d).

\section{PMN Microparticles Induce Extracellular ROS \\ Production in Nonstimulated PMNs and in Macrophages}

We evaluated whether $\mathrm{p} 47^{\text {phox }}$-enriched microparticles derived from LPS/fMLP-activated PMNs were capable of inducing ROS production by other nonstimulated
PMNs or macrophages. Figure 6 shows that microparticles released by LPS/fMLP-challenged PMNs, but not those produced spontaneously by control cells, were capable of inducing ROS production in freshly harvested and untreated PMNs (Fig. 6a). Importantly, ROS production induced by stimulated PMN-derived microparticles was exclusively extracellular (Fig. 6b), since no intracellular ROS production could be detected in that assay (not shown). Their effect on ROS production appeared to be

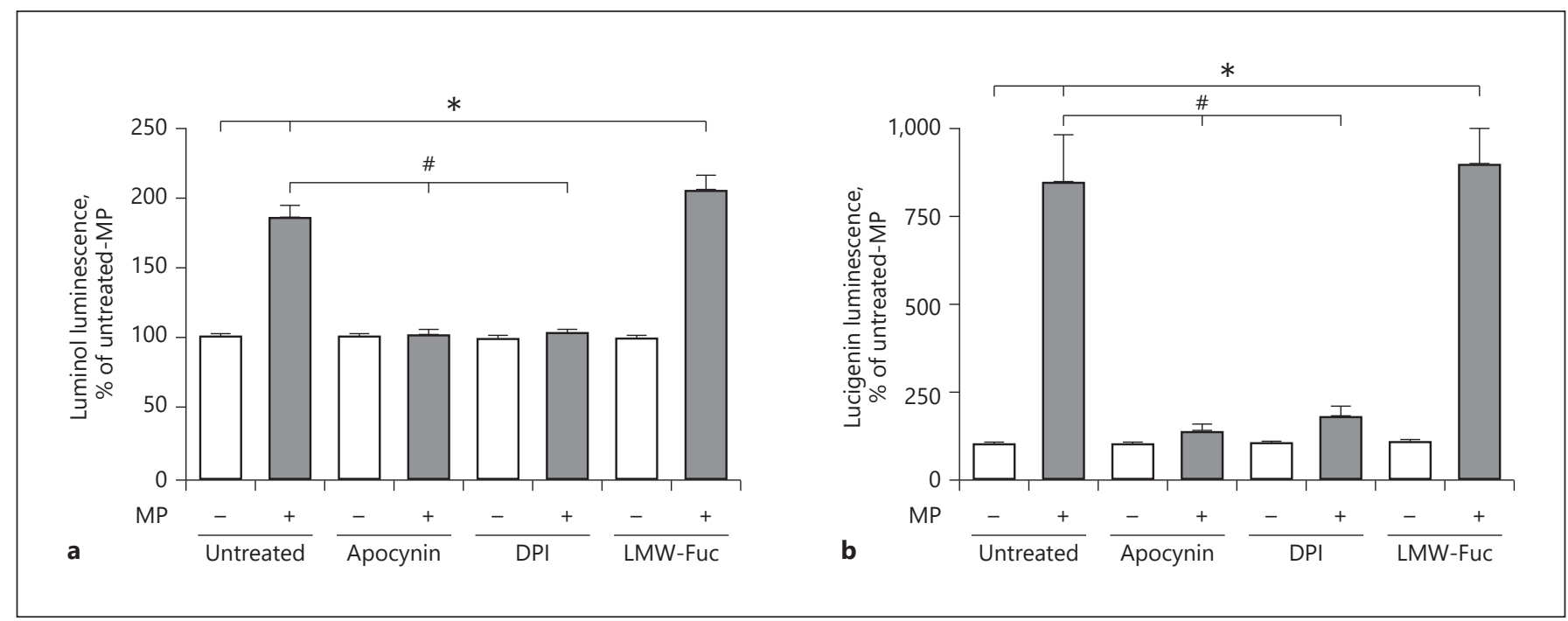

Fig. 6. Microparticles (MP) secreted by activated polymorphonuclear neutrophils (PMNs) induce reactive oxygen species (ROS) production in nonstimulated PMNs, which is not inhibited by lowmolecular-weight fucoidan (LMW-Fuc). Nonstimulated "acceptor" PMNs were incubated for $30 \mathrm{~min}$ at $37^{\circ} \mathrm{C}$ with MP released by PMNs that had been treated with $1 \mu \mathrm{g} / \mathrm{mL}$ lipopolysaccharide (LPS) and $100 \mathrm{nM} \mathrm{N}$-formyl-methionine-leucine-phenylalanine (fMLP) for $1 \mathrm{~h}$. Then, total ROS production (a) and extracellular ROS production (b) were analyzed using luminescence assays based on luminol or lucigenin, respectively. To evaluate if ROS

Fig. 5. Microparticle (MP) production by activated polymorphonuclear neutrophils (PMNs) is inhibited by low-molecular-weight fucoidan (LMW-Fuc). Human PMNs remained untreated or were treated with $10 \mu \mathrm{g} / \mathrm{mL}$ LMW-Fuc (LMW-Fuc group), $1 \mu \mathrm{g} / \mathrm{mL}$ lipopolysaccharide (LPS) for $5 \mathrm{~min}$ (priming) followed by stimulation with $100 \mathrm{nM} \mathrm{N}$-formyl-methionine-leucine-phenylalanine (fMLP) for $1 \mathrm{~h} \mathrm{(a} \mathrm{and} \mathrm{d)} \mathrm{or} 30 \mathrm{~min}$ (b and c) (LPS/fMLP group), or LPS primed for $5 \mathrm{~min}$, treated with LMW-Fuc for $5 \mathrm{~min}$, and then fMLP-stimulated (LPS/LMW-Fuc/fMLP group) for $30 \mathrm{~min}$ (a and b) or $1 \mathrm{~h}$ (c and d). All treatments were performed at $37^{\circ} \mathrm{C}$ (in a $5 \% \mathrm{CO}_{2}$ atmosphere). After treatment, PMNs were visualized by scanning electron microscopy (a) showing membrane blebs (a, b, and $\mathbf{d}$ ) and membrane ruffles (c). Membrane ruffles are indicated by white arrows. Scale bar: $2 \mu \mathrm{m}$. b Whole cell lysates of production was dependent on NOX2 activity, acceptor PMNs were preincubated with the general NADPH oxidase inhibitor (NOX) diphenyleneiodonium (DPI; $10 \mu \mathrm{M}$ ) or with the NADPH oxidase-2 (NOX2) inhibitor apocynin $(10 \mu \mathrm{M})$. Also, some samples were pretreated with $10 \mu \mathrm{g} / \mathrm{mL} \mathrm{LMW-Fuc} \mathrm{for} 5 \mathrm{~min}$ at $37^{\circ} \mathrm{C}$. Results are representative of three independent experiments. Data are displayed as means \pm SDM. ${ }^{*} p<0.05$ vs. untreated not incubated with MP; ${ }^{\#} p<0.05$ vs. corresponding sample not incubated with MP.

treated PMNs were subjected to SDS-PAGE and immunoblotting for the detection of myosin light chain (MLC) and phospho-MLC (pMLC). Densitometry of pMLC was performed using ImageJ, and results were normalized to MLC levels (loading control). Intact cells were removed by centrifugation, and supernatants were subjected to ultracentrifugation at $100,000 \mathrm{~g}$ for $4 \mathrm{~h}$, to produce a pellet containing MP. c MP released by treated PMNs were quantified using flow cytometry after labeling with annexin V. d Purified MP (1 $\mu \mathrm{g} / \mathrm{lane})$ were subjected to SDS-PAGE and Western blotting for the detection of $\mathrm{p} 47^{\text {phox }}$, a cytosolic subunit of NADPH oxidase-2 (NOX-2). Actin is shown as a loading control. Results are representative of four independent experiments. b, c Data are displayed as means \pm SDM. ${ }^{*} p<0.05$ vs. untreated; ${ }^{\#} p<0.05$ vs. treatment with LPS/fMLP. 


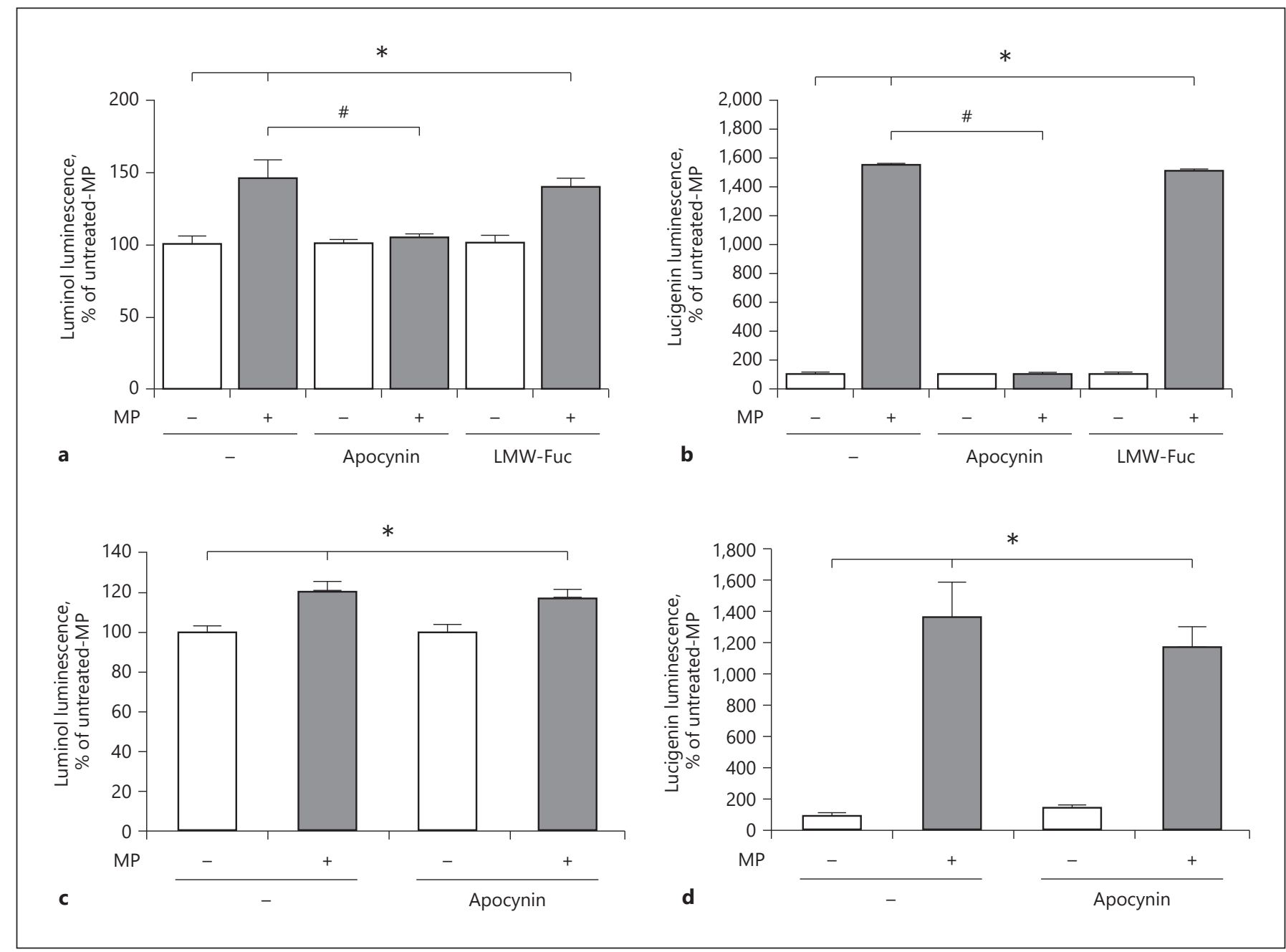

Fig. 7. Microparticles (MP) from activated polymorphonuclear neutrophils (PMNs) induce reactive oxygen species (ROS) production in macrophages, which is not inhibited by treatment with low-molecular-weight fucoidan (LMW-Fuc). Human monocytes isolated from healthy volunteers were plated and allowed to differentiate into macrophages for 7 days (at $37^{\circ} \mathrm{C}$, in $5 \% \mathrm{CO}_{2}$ ). $\mathrm{Mac}-$ rophages were stimulated with MP derived from PMNs treated with $1 \mu \mathrm{g} / \mathrm{mL}$ lipopolysaccharide (LPS) and $100 \mathrm{nM} \mathrm{N}$-formylmethionine-leucine-phenylalanine (fMLP; activated PMNs) for $1 \mathrm{~h}$. a Total macrophage ROS production (measured by luminol luminescence) was evaluated after $30 \mathrm{~min}$ of incubation with MP. CPS, luminescence counts/s. b Extracellular ROS production

dependent on NOX2 activity, because treatment with two different NOX2 inhibitors, the general NOX inhibitor diphenyleneiodonium (DPI; $10 \mu \mathrm{M}$ ) and the selective NOX2 inhibitor apocynin $(10 \mu \mathrm{M})$, abolished microparticle-induced ROS generation (Fig. 6a, b). Treatment of acceptor PMNs with LMW-Fuc did not inhibit microparticle-dependent ROS production (Fig. 6), suggesting that the in- (measured by lucigenin luminescence) was evaluated after $30 \mathrm{~min}$ of incubation. Macrophages were preincubated with the NADPH oxidase-2 (NOX2) inhibitor apocynin (10 $\mu \mathrm{M})$ or with LMW-Fuc $(10 \mu \mathrm{g} / \mathrm{mL})$. c, d Macrophages were left untreated, or were pretreated with apocynin for $15 \mathrm{~min}$. After pretreatment, cells were washed and then incubated with MP derived from activated PMNs for $30 \mathrm{~min}$. ROS was measured by lucigenin (c) and luminol (d) luminescence. All treatments were performed at $37^{\circ} \mathrm{C}$ (in $5 \%$ $\mathrm{CO}_{2}$ ). Results are representative of four independent experiments. Data are displayed as means \pm SDM. ${ }^{*} p<0.05$ vs. untreated not incubated with MP; ${ }^{*} p<0.05$ vs. treated group incubated with MP. hibitory effect of LMW-Fuc on ROS production by LPS/ fMLP-stimulated PMNs (shown at Fig. 4a, c) may be due to impairment of microparticle formation rather than direct antioxidant activity.

To investigate the putative interaction of those microparticles with other inflammatory cells, human macrophages were stimulated with PMN-derived microparti- 


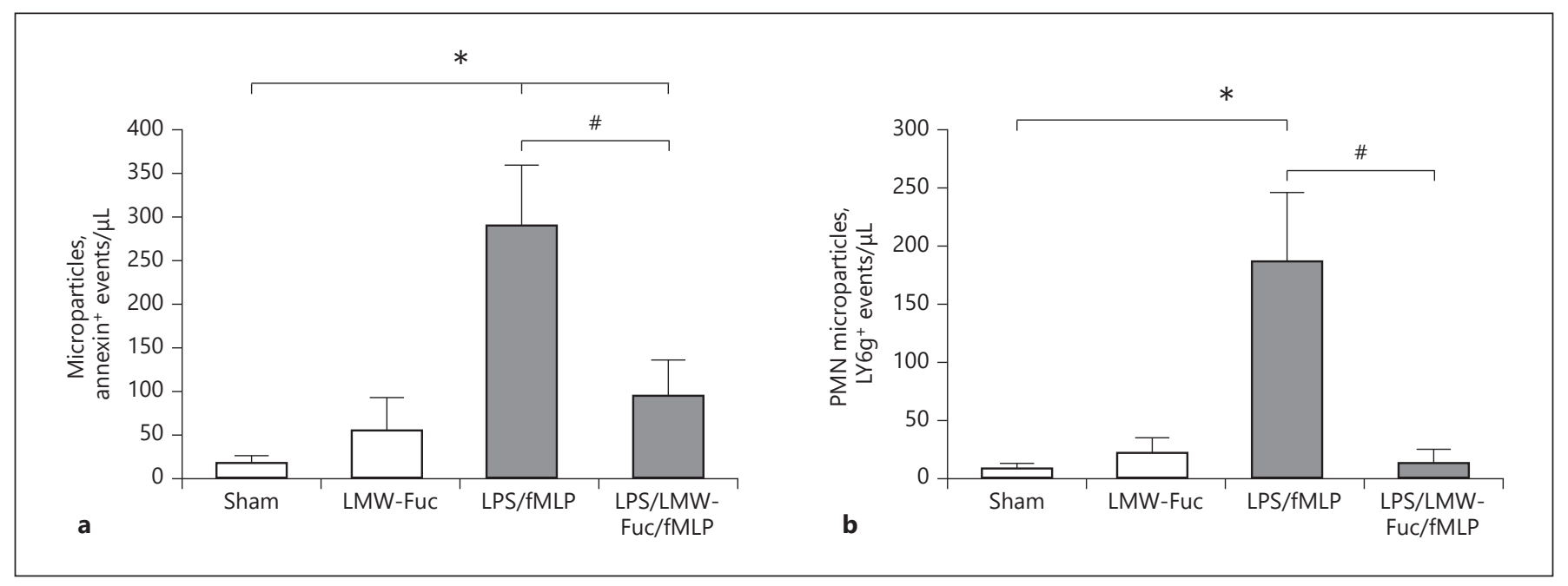

Fig. 8. Microparticle production induced in an endotoxemia model is inhibited by low-molecular-weight fucoidan (LMW-Fuc). Mice were subjected to one of the following treatments: sham (intraperitoneal injection [IP] $15 \mathrm{~min}$ of saline $0.9 \%+$ intravenous injection [IV] $15 \mathrm{~min}$ of saline $0.9 \%+$ IV $30 \mathrm{~min}$ of saline $0.9 \%$ ), LMW-Fuc (IP 15 min of saline $0.9 \%$ + IV 15 min of LMW-Fuc 25 $\mu \mathrm{g} / \mathrm{g}+\mathrm{IV} 30 \mathrm{~min}$ of saline $0.9 \%$ ), LPS/fMLP (IP 15 min of LPS 0.2 $\mu \mathrm{g} / \mathrm{g}+\mathrm{IV} 15 \mathrm{~min}$ of saline $0.9 \%+\mathrm{IV} 30 \mathrm{~min}$ of fMLP $100 \mathrm{nM}$ ) and LPS/LMW-Fuc/fMLP (IP $15 \mathrm{~min}$ of LPS $0.2 \mu \mathrm{g} / \mathrm{g}+\mathrm{IV} 15 \mathrm{~min}$ of
LMW-Fuc $25 \mu \mathrm{g} / \mathrm{g}$ + IV 30 min of fMLP $100 \mathrm{nM})$. After treatment, mice were euthanized and the collected plasma was submitted to a centrifugation to remove cells and debris, and the supernatant was subjected to ultracentrifugation at $100,000 \mathrm{~g}$ for $4 \mathrm{~h}$. Microparticles in the pellet were quantified by flow cytometry for annexin $\mathrm{V}^{+}(\mathbf{a})$ or $\mathrm{Ly}_{6 \mathrm{G}} \mathrm{G}^{(\mathbf{b})}$ events, using annexin $\mathrm{V}$ and anti-mouse Ly6G-PE (Biolegend, cat No. 127607). Results are representative of five independent experiments. Data are displayed as means \pm SDM. ${ }^{*} p<0.05$ vs. sham; ${ }^{*} p<0.05$ vs. treated with LPS/fMLP. cles. The microparticles originating from LPS/fMLP-activated PMNs also induced extracellular ROS generation by macrophages (Fig. 7a, b). This effect was inhibited by apocynin, but not by the treatment of macrophages with LMW-Fuc (Fig. 7a, b). Interestingly, when apocynin was removed from the medium, the microparticle effect on ROS production was restored (Fig. 7c, d), suggesting a role for $\mathrm{p} 47^{\text {phox }}$ present in microparticles.

\section{LMW-Fuc Inhibits Microparticle Generation in an Endotoxemia Model}

To evaluate a possible inhibitory effect in vivo of LMW-Fuc on microparticle generation, we established a model of endotoxemia in mice treated with both LPS and fMLP. For that, animals were injected with LPS, and after 30 min they were treated with fMLP. After 30 min of the last treatment, animals were euthanized, the blood was collected and the microparticles were purified from plasma samples. Figure 8 shows that mice treated with LPS/ fMLP presented a greater amount of circulating microparticles when compared to sham mice. The pre-treatment of LPS-injected animals with LMW-Fuc (15 min before the challenge with fMLP, in a similar timing protocol), inhibited almost completely the effects LPS/fMLP on microparticle generation (Fig. 8a). Corroborating our in vitro data, we show that microparticles isolated from plasma of LPS/fMLP-treated mice were mainly derived from PMNs (LY6G), and that the treatment with LMWFuc hindered the release of those PMN-derived microparticles (Fig. 8b). The gating strategy and the scatter plots can be observed in online supplementary Figure S6.

\section{Discussion}

In this work we provide new evidence on the anti-inflammatory properties of LMW-Fuc. We showed that LMW-Fuc was capable of inhibiting key pro-inflammatory activities in PMNs activated by exposure to bacterial products (LPS and fMLP). Notably, we also demonstrated that pro-inflammatory stimuli induced the release of microparticles by activated PMNs, which could function as paracrine communication agents, inducing extracellular ROS production in unstimulated macrophages. The pretreatment with LMW-Fuc suppressed microparticle formation in vitro and in vivo by activated PMNs. On the other hand, LMW-Fuc did not prevent in vitro microparticle-induced ROS production. 
We have used a classic model of PMN activation in vitro that, similar to a septic condition, sequentially expose cells to bacterial products. Although both agents had shown effects when assayed alone, LPS had a weak effect on PMN chemotaxis, and fMLP was weak to abrogate cell apoptosis and induce ROS production, when compared to the LPS/fMLP challenge, used throughout this work. Corroborating our strategy, Itakura et al. [26] showed that fMLP induced microparticle formation by PMNs from systemic inflammatory response syndrome patients. Supporting the data, we showed that endotoxemia induced in mice by LPS/fMLP challenge promoted, in vivo the generation, of neutrophil-derived microparticle, an effect also inhibited by the treatment of mice with LMW-Fuc.

Malhotra et al. [27] showed that fucoidan pretreatment inhibited the effect of LPS priming on PMNs. We confirmed these results, showing that treatment with LMW-Fuc, before LPS priming, prevented the effect of fMLP on PMN migration and the apoptosis delay (see online suppl. Fig. S1 C and D). Moreover, we have also shown here that LMW-Fuc treatment after LPS challenge is also capable of inhibiting the fMLP effect on PMN cytoskeleton rearrangement, preventing fMLP stimulation, as can be observed in online supplementary Figure S7. Supporting this hypothesis, LMW-Fuc also inhibited the LPS/fMLP-induced activation of AKT, a key component of the canonical PI3K/AKT pathway involved in the regulation of actin polymerization and other cytoskeleton-associated events [28]. When activated, AKT phosphorylates the pro-apoptotic protein Bad, leading to Bad degradation [29]. Once committed to a spontaneous apoptotic program, PMNs express high levels of proapoptotic proteins and low levels of antiapoptotic molecules. Activation of these cells during inflammation activates PI3K/AKT pathway, switching to a survival mechanism that includes rapid Bad degradation and slow increase in the expression of antiapoptotic proteins [17, 30]. LMW-Fuc inhibited AKT phosphorylation and impaired Bad degradation, interrupting the antiapoptotic effect triggered by LPS/fMLP stimulation. These results suggest that the pro-apoptotic effect of LMW-Fuc on PMNs might involve regulation of the intrinsic apoptotic pathway. Thus, LMW-Fuc impairs chemotactic PMN migration and PMN survival, two important features of PMN activation associated with the establishment of chronic inflammatory conditions [31].

In many cell types, including PMNs, intracellular ROS production modulates different signaling pathways involved in modulation of cellular activation, functions, and survival. In PMNs, ROS also exert a crucial microbicidal effect killing, when released inside pathogen-containing phagosomes [6]. However, exacerbated PMN activation may lead to excessive ROS generation, with "leakage" of ROS to the extracellular environment, which is potentially harmful to hosts [32]. The major source of ROS in PMNs is the NOX2 system [33]. As expected, stimulation by LPS/fMLP induced intra- and extracellular ROS production by PMNs. LMW-Fuc treatment did not impair the intracellular production of ROS. In contrast, the release of ROS to extracellular milieu by LPS/ fMLP-treated PMNs was abolished by treatment with LMW-Fuc. These results are particularly interesting because they suggest that treatment with LMW-Fuc could prevent tissue injury caused by exacerbated inflammation at infection sites, by inhibiting extracellular ROS production by activated PMNs, without affecting the intracellular ROS production. We also tested LMW-Fuc directly in a cell-free system and did not detect antioxidant properties of this polysaccharide (not shown). Furthermore, we also observed that although LMW-Fuc did not inhibit LPS/fMLP-induced intracellular ROS production, measured through DCF probe, it was able to inhibit NET generation. So, when we performed an assay with a more sensitive probe to hypochlorous acid (APF), we observed that LMW-Fuc abrogated LPS/fMLP-induced effect on its production. This result is in agreement with the literature, which demonstrated that MPO-derived hypochlorous acid production is essential to NET generation [7].

Cell activation often leads to the release of microparticles by activated cells [34]. These structures are present at high levels in plasma during sepsis [35], and recent studies have shown that fMLP is capable of inducing microparticle formation by PMNs $[26,36,37]$. PMN microparticles are covered with L-selectin molecules, indicating that their formation by vesiculation occurs from Lselectin-rich membrane domains [25]. Here, we showed that treatment of PMNs with LPS/fMLP for $1 \mathrm{~h}$ induced the formation of microparticles that were rich in phosphatidylserine (annexin $\mathrm{V}^{+}$) and L-selectin, and that LMW-Fuc inhibited microparticle generation by activated PMNs.

L-selectin shedding is a known marker of PMN activation, and fucoidans are able to recognize and bind to Lselectin [13]. Thus, the inhibitory effects of LMW-Fuc on activated PMN function and microparticle formation could be related to L-selectin binding. We hypothesized that LMW-Fuc binds to L-selectin on the surface of PMNs, modifying the arrangement of L-selectin molecules on the cell surface and, consequently, impairing mi- 
croparticle formation by vesiculation. This hypothesis seems reasonable, because LMW-Fuc delayed L-selectin shedding induced by LPS/fMLP treatment, and unstimulated PMNs treated with LMW-Fuc had equal levels of L-selectin when compared to untreated cells. Therefore, we propose that LMW-Fuc inhibits microparticle vesiculation induced by LPS/fMLP challenge, but allows the shedding of L-selectin not associated with membrane ectosomes of activated cells.

These results suggest that LMW-Fuc inhibition of microparticle formation by vesiculation is a complex event which may depend on several protein interactions in highly specialized areas of the plasma membrane. We observed that LPS/fMLP induces MLC activation in PMNs, and that this effect was abolished when PMNs were treated with LMW-Fuc. Moreover, pretreatment of PMNs with the ROCK inhibitor Y-27632 impaired microparticle generation in LPS/fMLP-challenged cells, indicating that the ROCK/MLC pathway is the major route responsible for microparticle formation by PMNs in our model. Taken together, these data suggest that the inhibitory effect of LMW-Fuc on microparticle release by activated PMNs results from modulation of the activity of specific signaling pathways associated with PMNs activation.

Microparticles have components from their parental cell and also share some similar functions with these cells [36]. In agreement with these data, we observed that LPS/ fMLP-stimulated PMN microparticles are positive for the PMNs marker CD66 ${ }^{+}$. Microparticle contents also depend on the stimuli responsible for their formation and the microenvironment of the parental cell [38-40]. Recently, cell-derived microparticles have been described as novel mediators of paracrine communication [41]. Also, the presence of functional NOX subunits in microparticles has already been reported [42], and their role as redox-active mediators has been proposed [43]. We showed that LPS/fMLP treatment led to the generation of PMN microparticles which contain $\mathrm{p} 47^{\text {phox }}$, a cytosolic NOX2 subunit, and that these microparticles are also capable of inducing ROS production both in PMNs and in macrophages not subjected to previous stimulation. Similar to neutrophils, macrophages also possess the NOX2 complex machinery, which plays an important role in the inflammatory microenvironment [4]. Interestingly, we observed that the effect of microparticles on ROS production relies on NOX2 activity in "acceptor" PMNs and macrophages (those stimulated with microparticles), since ROS production was abolished by the NOX2 inhibitor apocynin. We also showed that $\mathrm{p} 47^{\text {phox }}$ from microparticles is involved in its effect on ROS production once we observed that when just $\mathrm{p} 47^{\text {phox }}$ from macrophages was inhibited (apocynin was removed), the microparticle effect was not abolished. These results suggest that PMN microparticles may act as autocrine or paracrine stimulators, fusing to acceptor cell membranes, which induces microparticle $\mathrm{p} 47^{p h o x}$ to interact with the cell membrane NOX2 subunit GP91 ${ }^{\text {phox }}$, culminating in extracellular ROS production (Fig. 7). Importantly, although activated-PMN microparticles induced ROS production in freshly harvested and untreated PMNs, the microparticles per se are not capable of producing ROS (not shown) since they do not have a complete NOX2 machinery.

Dalli et al. [37] described an anti-inflammatory role of PMN microparticles released upon fMLP treatment. These microparticles contain functionally active annexin 1, a known lipid mediator of inflammation resolution, and are capable of inhibiting cell recruitment when adhered to endothelial cells. The main difference between those studies and ours lies in the pre-activation conditions. In our model, LPS priming is responsible for triggering pro-inflammatory signaling in PMNs, inducing the translocation of $\mathrm{p} 47^{\text {phox }}$ to the cell membrane. Then, further stimulation with fMLP is necessary to promote the formation and extrusion of p $^{7^{\text {phox }}}$-enriched microparticles. We also observed that LPS alone did not induce PMN microparticle generation (not shown). On the other hand, fMLP alone induced the production of large amounts of PMN microparticles and, in agreement with Dalli et al. [36, 37], these microparticles had no effect on ROS production by freshly harvested and untreated PMNs (not shown). These data reinforce the notion that the pro-inflammatory role of PMN microparticles generated by LPS/fMLP is due to microparticle $\mathrm{p} 47^{\text {phox }}$ content. ROS production triggered by ectosomes could be implicated in many inflammatory conditions, and the elucidation of the molecular events responsible for the signaling triggered by microparticles might aid in the rational design of selective anti-inflammation therapies, particularly those aiming to control chronic inflammatory disorders.

\section{Conclusion}

In conclusion, we show that LMW-Fuc negatively modulates the pro-inflammatory functions of activated PMNs. The findings showing the ability of microvesicles released by LPS/ fMLP-stimulated PMNs to transfer p47phox NOX2 subunits to other cells, specially phagocytes, are novel data that can be further explored for a better understanding of the amplification of a bacterial 
inflammatory response. Moreover, the data demonstrating that LMW-Fuc is able to inhibit, both in vitro and in vivo, the release of PMN-derived microparticles have pointed to a potential target for controlling or modulating the harmful effects of systemic inflammation associated with bacterial infections.

\section{Acknowledgements}

We thank Genilson Rodrigues da Silva and Gabriele Muniz for technical assistance and Prof. Marcia Christina Amorim Moreira Leite for access to the Electron Microscopy Laboratory of the Insituto de Química (UERJ).

The manuscript was reviewed by a professional science editor and by a native English-speaking copy editor to improve readability.

\section{Statement of Ethics}

Human monocytes and PMNs were isolated from human blood collected from healthy volunteers at the Pedro Ernesto Hospital (Rio de Janeiro State University - UERJ, RJ, Brazil). Study approval was obtained (38257914.7.0000.5259) from the Ethics Committee of the Pedro Ernesto Hospital and all volunteers gave written informed consent for participation in the study.

This study was carried out in strict accordance with the recommendations in the Guide for the Care and Use of Laboratory Animals of the National Institutes of Health. The protocol was approved by the Committee on the Ethics of Animal Experimental of Federal University of Rio de Janeiro (Permit number: CEUA/ 003/2013).

\section{Disclosure Statement}

The authors report no conflict of interest.

\section{Funding Sources}

This work was supported by grants from the Fundação de Amparo à Pesquisa do Estado do Rio de Janeiro (FAPERJ: E-26/ 202.782/2017), Coordenação de Aperfeiçoamento de Pessoal de Nível Superior (CAPES) (Finance Code 001) and Conselho Nacional de Desenvolvimento Científico e Tecnológico (CNPq: 302413/2017-0).

\section{References}

1 Kolaczkowska E, Kubes P. Neutrophil recruitment and function in health and inflammation. Nat Rev Immunol. 2013 Mar;13(3): 159-75.

2 Herter J, Zarbock A. Integrin Regulation during Leukocyte Recruitment. J Immunol. 2013 May;190(9):4451-7.

3 Mantovani A, Cassatella MA, Costantini C, Jaillon S. Neutrophils in the activation and regulation of innate and adaptive immunity. Nat Rev Immunol. 2011 Jul;11(8):519-31.

4 Wirthmueller U, Baggiolini M, de Weck AL, Dahinden CA. Receptor-operated activation of polymorphonuclear leukocytes: different effects of NAP-1/IL-8 and fMet-Leu-Phe or C5a. Biochem Biophys Res Commun. 1991 May;176(3):972-8.

5 Dröge W. Free radicals in the physiological control of cell function. Physiol Rev. 2002 Jan; 82(1):47-95.

6 Dupré-Crochet S, Erard M, Nüße O. ROS production in phagocytes: why, when, and where? J Leukoc Biol. 2013 Oct;94(4):657-70.

7 Björnsdottir H, Welin A, Michaëlsson E, Osla V, Berg S, Christenson K, et al. Neutrophil NET formation is regulated from the inside by myeloperoxidase-processed reactive oxygen species. Free Radic Biol Med. 2015 Dec;89: 1024-35.

8 Zawrotniak M, Rapala-Kozik M. Neutrophil extracellular traps (NETs) - formation and implications. Acta Biochim Pol. 2013;60(3): $277-84$.
9 Jiang S, Park DW, Tadie JM, Gregoire M, Deshane J, Pittet JF, et al. Human resistin promotes neutrophil proinflammatory activation and neutrophil extracellular trap formation and increases severity of acute lung injury. J Immunol. 2014 May;192(10):4795-803.

10 Itakura A, McCarty OJ. Pivotal role for the mTOR pathway in the formation of neutrophil extracellular traps via regulation of autophagy. Am J Physiol Cell Physiol. 2013 Aug; 305(3):C348-54.

11 Mesri M, Altieri DC. Endothelial cell activation by leukocyte microparticles. J Immunol. 1998 Oct; 161(8):4382-7.

12 Sadallah S, Eken C, Schifferli JA. Ectosomes as modulators of inflammation and immunity. Clin Exp Immunol. 2011 Jan;163(1):26-32.

13 Preobrazhenskaya ME, Berman AE, Mikhailov VI, Ushakova NA, Mazurov AV, Semenov AV, et al. Fucoidan inhibits leukocyte recruitment in a model peritoneal inflammation in rat and blocks interaction of P-selectin with its carbohydrate ligand. Biochem $\mathrm{Mol}$ Biol Int. 1997 Oct;43(2):443-51.

14 Zemani F, Benisvy D, Galy-Fauroux I, Lokajczyk A, Colliec-Jouault S, Uzan G, et al. Lowmolecular-weight fucoidan enhances the proangiogenic phenotype of endothelial progenitor cells. Biochem Pharmacol. 2005 Oct;70(8): 1167-75.
15 Sarlon G, Zemani F, David L, Duong Van Huyen JP, Dizier B, Grelac F, et al. Therapeutic effect of fucoidan-stimulated endothelial colony-forming cells in peripheral ischemia. J Thromb Haemost. 2012 Jan;10(1):38-48.

16 Guthrie LA, McPhail LC, Henson PM, Johnston RB Jr. Priming of neutrophils for enhanced release of oxygen metabolites by bacterial lipopolysaccharide. Evidence for increased activity of the superoxide-producing enzyme. J Exp Med. 1984 Dec;160(6):1656-71.

17 Saldanha-Gama RF, Moraes JA, MarianoOliveira A, Coelho AL, Walsh EM, Marcinkiewicz C, et al. alpha(9)beta(1) integrin engagement inhibits neutrophil spontaneous apoptosis: involvement of Bcl-2 family members. Biochim Biophys Acta. 2010 Jul;1803(7): 848-57.

18 Amendola RS, Martin AC, Selistre-de-Araújo HS, Paula-Neto HA, Saldanha-Gama R, Barja-Fidalgo C. ADAM9 disintegrin domain activates human neutrophils through an autocrine circuit involving integrins and CXCR2. J Leukoc Biol. 2015 May;97(5):951-62.

19 Yuan SY, Shen Q, Rigor RR, Wu MH. Neutrophil transmigration, focal adhesion kinase and endothelial barrier function. Microvasc Res. 2012 Jan;83(1):82-8.

20 Gabelloni ML, Trevani AS, Sabatté J, Geffner J. Mechanisms regulating neutrophil survival and cell death. Semin Immunopathol. 2013 Jul;35(4):423-37. 
21 Heit B, Tavener S, Raharjo E, Kubes P. An intracellular signaling hierarchy determines direction of migration in opposing chemotactic gradients. J Cell Biol. 2002 Oct;159(1):91102.

22 DeLeo FR, Renee J, McCormick S, Nakamura M, Apicella M, Weiss JP, et al. Neutrophils exposed to bacterial lipopolysaccharide upregulate NADPH oxidase assembly. J Clin Invest. 1998 Jan;101(2):455-63.

23 Rochon YP, Simon SI, Lynam EB, Sklar LA. A role for lectin interactions during human neutrophil aggregation. J Immunol. $1994 \mathrm{Feb}$; 152(3):1385-93.

24 VanWijk MJ, VanBavel E, Sturk A, Nieuwland R. Microparticles in cardiovascular diseases. Cardiovasc Res. 2003 Aug;59(2):27787.

25 Nolan S, Dixon R, Norman K, Hellewell P, Ridger V. Nitric oxide regulates neutrophil migration through microparticle formation. Am J Pathol. 2008 Jan;172(1):265-73.

26 Itakura Sumi Y, Ogura H, Tanaka H, Koh T, Fujita K, Fujimi S, et al. Paradoxical cytoskeleton and microparticle formation changes in monocytes and polymorphonuclear leukocytes in severe systemic inflammatory response syndrome patients. J Trauma. 2003 Dec;55(6):1125-32.

27 Malhotra R, Priest R, Bird MI. Role for L-selectin in lipopolysaccharide-induced activation of neutrophils. Biochem J. 1996 Dec; 320(Pt 2):589-93.

28 Sen P, Mukherjee S, Ray D, Raha S. Involvement of the Akt/PKB signaling pathway with disease processes. Mol Cell Biochem. 2003 Nov;253(1-2):241-6.
29 Blume-Jensen P, Janknecht R, Hunter T. The kit receptor promotes cell survival via activation of PI 3-kinase and subsequent Akt-mediated phosphorylation of Bad on Ser136. Curr Biol. 1998 Jun;8(13):779-82.

30 Morel O, Jesel L, Freyssinet JM, Toti F. Cellular mechanisms underlying the formation of circulating microparticles. Arterioscler Thromb Vasc Biol. 2011 Jan;31(1):15-26.

31 Wright HL, Moots RJ, Bucknall RC, Edwards SW. Neutrophil function in inflammation and inflammatory diseases. Rheumatology (Oxford). 2010 Sep;49(9):1618-31.

32 Brieger K, Schiavone S, Miller FJ Jr, Krause KH. Reactive oxygen species: from health to disease. Swiss Med Wkly. 2012 Aug; 142:w13659.

33 Sareila O, Kelkka T, Pizzolla A, Hultqvist M, Holmdahl R. NOX2 complex-derived ROS as immune regulators. Antioxid Redox Signal. 2011 Oct;15(8):2197-208.

34 Burnier L, Fontana P, Kwak BR, AngelilloScherrer A. Cell-derived microparticles in haemostasis and vascular medicine. Thromb Haemost. 2009 Mar;101(3):439-51.

35 Nieuwland R, Berckmans RJ, McGregor S, Böing AN, Romijn FP, Westendorp RG, et al. Cellular origin and procoagulant properties of microparticles in meningococcal sepsis. Blood. 2000 Feb;95(3):930-5.

36 Dalli J, Montero-Melendez T, Norling LV, Yin X, Hinds C, Haskard D, et al. Heterogeneity in neutrophil microparticles reveals distinct proteome and functional properties. Mol Cell Proteomics. 2013 Aug;12(8):220519.

37 Dalli J, Norling LV, Renshaw D, Cooper D, Leung KY, Perretti M. Annexin 1 mediates the rapid anti-inflammatory effects of neutrophil-derived microparticles. Blood. 2008 Sep; 112(6):2512-9.
38 Peterson DB, Sander T, Kaul S, Wakim BT, Halligan B, Twigger S, et al. Comparative proteomic analysis of PAI-1 and TNF-alpha-derived endothelial microparticles. Proteomics. 2008 Jun;8(12):2430-46.

39 Fourcade O, Simon MF, Viodé C, Rugani N, Leballe F, Ragab A, et al. Secretory phospholipase A2 generates the novel lipid mediator lysophosphatidic acid in membrane microvesicles shed from activated cells. Cell. 1995 Mar;80(6):919-27.

40 Dolo V, Ginestra A, Cassarà D, Violini S, Lucania G, Torrisi MR, et al. Selective localization of matrix metalloproteinase 9 , beta1 integrins, and human lymphocyte antigen class I molecules on membrane vesicles shed by 8701-BC breast carcinoma cells. Cancer Res. 1998 Oct;58(19):4468-74.

41 Mause SF, Weber C. Microparticles: protagonists of a novel communication network for intercellular information exchange. Circ Res. 2010 Oct;107(9):1047-57.

42 Janiszewski M, Do Carmo AO, Pedro MA, Silva E, Knobel E, Laurindo FR. Platelet-derived exosomes of septic individuals possess proapoptotic $\mathrm{NAD}(\mathrm{P}) \mathrm{H}$ oxidase activity: A novel vascular redox pathway. Crit Care Med. 2004 Mar;32(3):818-25.

43 Gambim MH, do Carmo AO, Marti L, Veríssimo-Filho S, Lopes LR, Janiszewski M. Platelet-derived exosomes induce endothelial cell apoptosis through peroxynitrite generation: experimental evidence for a novel mechanism of septic vascular dysfunction. Crit Care. 2007;11(5):R107. 